\title{
Prevention of the cardiovascular diseases - with natural antioxidants
}

\author{
KóróDI Gyula MD ${ }^{1}$
}

\begin{abstract}
Cardiovascular diseases are the leading cause of death worldwide. Non-fatal cardiovas- cular episodes suffered by hundreds of millions of people present an enormous burden even on the most developed health care systems. The amelioration of the mortality and morbidity of the working population has a tremendous economic impact. The increase of the life expectancy at birth by 10 percent could result in a 0,4 percent GDP growth in the economy. With early detection of the risk factors of cardiovascular episodes and with normalization of risk factors we can find a more effective method for preventing cardiovascular disease.
\end{abstract}

Keywords: cardiovascular diseases, oxidative stress, natural antioxidants, risk estimation

\section{The Hungarian cardiovascular data}

Hungarian cardiovascular mortality and morbidity statistics show a significant backlog in compar- ison to the similar European statistics. The life expectancy at birth has grown by 3 years in the last two decades (in truth the growth was realized only in the past 5 years) in Hungary. In the meantime the higher European life expectancy at birth has risen almost 5 years and Hungary has only passed the Baltic States in this ranking.

The picture is even worse when we consider the disability adjusted life expectancy (DALE), that is the measure of years lived minus an estimated percentage for each year lived in incomplete health. Hungarians are 8 years behind their European counterparts regarding the DALE statistics and again are only above the Baltic statistics.

In more than half the cases the leading cause of death is cardiovascular disease. It is worth analyzing premature mortality (mortality under the age of 65) because this effects the working pop- ulation and therefore the productivity of the economy. The number of premature mortalities due to cardiovascular diseases in Hungary is 2,5 times higher than in the European union and again only the Baltic states have worse statistics. The scary phenomenon is supported by a survey run among middle aged people that found $40 \%$ of respondents say they have cardiovascular disease.

Numerous risk factors for cardiovascular disease are known. Most of them relate to lifestyle (smoking, excessive alcohol consumption, bad eating habits, inadequate physical activity), but other risk factors like environmental factors, genetics, or geographical differences in access to a health care system could significantly influence mortality and morbidity.

1 Quatos Ltd. Email: korodigy@ freemail.hu

\section{Early detection of the risk factors of cardiovascular episodes}

With the result of our scientific research my goal is to invest in an area that evidently promotes economic development and increases economic competitiveness on the long run. In the meantime the investment will cut social and health care expenditures and even create new jobs. My aim is to launch such a public health program that could indicate cardiovascular diseases in earlier stages than we do now and could effectively influence cardiovascular risk factors before the onset of cardiovascular symptoms. As a result we could suppress the development of cardiovascular diseases and could help the unfavourable mortality and morbidity statistics of the Hungarian population.

Research and clinical observations show that in the first stage of cardiovascular diseases - in the process of endothelial damage - the oxidation of lipids is one of the most important factors. The "French Paradox" was described in the 1990's and it observed the phenomena in France where cardiovascular mortality was significantly lower than in similarly developed countries. The phe- nomena were explained by the high volume of polyphenol type anti-oxidants found in red wine.

Following the above logic I am planning to follow-up the oxidative stress stage in patients with multiple cardiovascular risk factors (smokers, obese-, hypertensive, diabetes patients and patients with elevated blood lipid and cholesterol levels). My first goal is create a simple and cost-effective method to detect "Total Antioxidant Status (TAS)" from blood and urine. This method should enable us to measure TAS in large populations and therefore I can follow the effectiveness of treatment and the effectiveness of preventing cardiovascular episodes in the risk population. The currently used TAS measuring system (expensive and not cost-effective for public health screening) will serve as a control method to validate the accuracy of our 
measurements from serum and urine samples.

Mostly the LDL-cholesterol fraction of blood lipids, specifically the oxydated type can be blamed for the endothel damage that is the onset of atherosclerosis. In summary I am aiming to develop a method that is able to simply and costeffectively measure the oxydated serum LDL-cho- lesterol level. The elevation of serum homocystein concentration could be an early indicator of cardiovascular episodes. Measurement of serum homocystein is costly and the availability is lim- ited therefore it is not widely used in clinical practice. I am planning to develop a simple, fast and inexpensive method to measure the serum homocystein level.

\section{Normalization of risk factors to prevent cardiovascular episodes}

The introduction of the above measuring methods in daily screening routines would result in an earlier and more sensitive prognosis in the risk of cardiovascular episodes. A shift in the focus from therapy to prevention could be observed even in Hungary. More effective screening methods and more focus on workplace health could open up new routes to prevention, where the use of healthy nutrition, dietary supplements and health-centered lifestyle enjoy increased emphasis besides pharmaceuticals.

Polyphenols derived from grapes have several observed cardiovascular effects. With the careful evaluation of antioxidants, the impact of these molecules is clearly recognizable on cellular and tissue levels. The action of antioxidants is generally comprised of the capture of free radicals. As a result antioxidants have a cardio-, neuro- and tumour protective function. Widely known facts are that environmental, lifestyle factors and diseases could diminish the resistance of the human body against free radicals. The natural protection of the human body could be ameliorated with a supplement of antioxidants from an external source. Almost all vegetables contain significant amounts of antioxidants but in the skin and seed of blue grapes there are an enormous amount of

Kóródi Gyula Md: Prevention of the cardiovascular diseases - with natural antioxidants

antioxidant polyphenol derivatives. With various isolation techniques the molecules could be sep- arated and with a linear accelerator the electron donor (antioxidants) capacity could be determined. We could rank the antioxidants with the previously mentioned methods and could isolate the most potent antioxidant molecule. Various antioxidant molecules could be evaluated in combination to test for synergic or cumulative effect. Through these methods the most potent molecules and their combinations could be further tested to maximize the preventive and therapeutic usage.

The skin and seed of red grapes contain the most amount of polyphenol. High concentrations of polyphenol still remains in grapes (the squeezed form of grapes in vintage) and even in the rem- nant of the distilled grape (polyphenols are heat stable molecules). My goal is to develop a dietary supplement from the "remnant" of the distilled grape by taking advantage of its organoleptic and antioxidant features. "Functional foods" could be produced with the usage of this $100 \%$ natural admixture in the meat, milk, mill and spice industry. Eventually, the above food product line could be well used in society to prevent cardiovascular diseases.

red grape extracts are in commercial use these days, but the effectiveness of these products has not been scientifically tested either "in vitro", nor "in vivo" researches. Based on our tests run in the past years we judge that a research program is needed and rational that could synthesize the above clear goals into a cross-disciplinary system comprising basic research, applied research, technology development and public health. The project would like to screen the oxidative stress status, as a significant cardiovascular risk with sensitive screening methods in an earlier stage and thus prevent cardiovascular diseases with dietary supplements and functional (contains anti- oxidant admixtures) foods, something akin to a "non-alcoholic French paradox". The developed new generational supplements and admixtures would be made out of the Hungarian blue grape. The physical-, chemical-, and biological examination of molecules derived from the isolation of grape polyphenols could result in higher efficiency, a controlled composition food supplement, and admixtures with various economic availability. Finally, the isolated polyphenols could possibly be the basis for future pharmaceutical research.

We could derive data from basic research in regards to the antioxidant capacity of grape poly- phenols and the scientific evaluation if it's biological efficiency. We could develop new generation- al antioxidant food supplements based on the results of the basic research findings. "In vivo" testing could result in a useful preventive and therapeutic product against diseases that are accompanied by oxidative stress (like cardiovascular). Finding a method that measures antioxidant capacity in blood serum and urine could be a widely used public health screening method. Marketable food 4supplements, admixtures, the development of functional foods and incidentally pharmaceutical products could be a result of the project. The wide distribution of these products with the above scientific background could improve the health status of society.

\section{Summary}

The exploitation of these possibilities and the expected economic results of the project are the following. This project makes top priority among $\mathbf{r} \& \mathrm{D}$ targets the improvement of life quality and the prevention of cardiovascular diseases (the leading cause of death). The goal of our scientific research work is to implement continuity from basic and applied research, technological inno- vation to the initiation of our products on the market. The proposal has a clear objective, for its achievement a complex approach and the cooperation of several technological areas is necessary. This is mainly valid for medical, physical and chemical areas that should be supported by such indispensable elements like creativity and productive 
experience.

The conformity of the project proposal clearly suits the objectives of the program, it contains internationally acceptable scientific consequences and given intellectual products with new tech- nologies, equipments, furnishings and materials. The collaboration of a small enterprise with re- search units of the Hungarian Academy of Sciences and the leading medical research institutes of Hungary can produce original results for preventive medical practice.

One of the basic objectives of our work is to clear up the biochemical aspects of the risk factors of illnesses demonstrated by medical investigations. We would like to create a national health-care program based on early diagnostic and preventive therapeutic possibilities to improve the morbidi- ty and mortality rates. The new method can indicate the "oxidative stress" in an early stage, and the "functional food-products", foodsupplements, (pharmaceutical products) can treat it effectively and reduce the cardiovascular mortality.

This paper was supported by the János Bolyai Research Scholarship of the Hungarian Academy of Sciences.

\section{References}

AHErNE, S. Aisling - O’BrIEN, Nora M. (2002): Dietaryflavonols: Chemistry, food content, and me- tabolism.In: Nutrition. 18. p. 75-81. https://doi.org/10.1016/S0899-9007(01)00695-5

BIró György - DWOrSCHÁK ernő-ZAJKÁS Gábor (1997): Élelmiszerek az egészségmegőrzésben. Bu- dapest, Béres rt. p. 113.

HALLIWELL, Barry (1996): Antioxidants. In ZIEGLEr, Ekhard E. - FILEr, L. J. Jr. (eds.): Present knowledge in nutrition. 7. ed. Washington D.C., ILSI Press. p. 596-603.

HENNEKENS, Charles H. (1998): Antioxidant vitamins and cardiovascular disease: Current knowledge and future directions. In: Nutrition. 14. p. 50-51. https://doi.org/10.1016/S0899-9007(97)00393-6

LÁSZLó Valéria - FALuS András (2002): Az öregedés sejttani és genetikai alapjai. In: Magyar Tudomány. XLVIII. p. 406-411.

LuGASI Andrea (2000): Az élelmiszer eredetű flavonoidok potenciális egészségvédő hatása. In: Orvosi Hetilap. 141. p. 1751-1760.

NIJVELDT, robert J. - NOOD, Els van - HOOrN, Danny E. C. van - BOELENS, Petra G. - NOrrEN, Klaske van LEEuWEN, Paul A. M. van (2001): Flavonoids: a review of probable mechanism of action and potential applications. In: American Journal of Clinical Nutrition. 74. p. 418-425.

WAHLQVIST, Mark L (2001): Principles in the development of novel and functional foods. In: NAFAS Science. 4. p. 31-35. 